\title{
Modulation of regularity and lexicality effects in reading aloud
}

\author{
SACHIKO KINOSHITA \\ Macquarie University, Sydney, Australia \\ STEPHEN J. LUPKER \\ University of Western Ontario, London, Ontario, Canada \\ and \\ KATHLEEN RASTLE \\ Royal Holloway University of London, London, England \\ and Macquarie University, Sydney, Australia
}

\begin{abstract}
We examined the question of whether the sizes of the regularity and lexicality effects in naming can be modulated as a function of filler type (nonwords or low-frequency exception words). The lexicality effect was larger in the exception word filler condition than in the nonword filler condition, but the size of the regularity effect was essentially unaffected by filler type. This pattern is at odds with what is generally assumed to be the predictions from dual-route theories of reading aloud. An attempt was next made to determine whether the dual-route cascaded model of Coltheart, Rastle, Perry, Langdon, and Ziegler (2001) could possibly simulate this pattern when changes were introduced to each of the three parameters that affect the contribution of the nonlexical route. We discuss the implications of these results for the idea that reliance on the lexical and nonlexical routes is under strategic control.
\end{abstract}

The basic premise of Coltheart and colleagues' (Coltheart, 1978; Coltheart, Curtis, Atkins, \& Haller, 1993; Coltheart, Rastle, Perry, Langdon, \& Ziegler, 2001; Paap $\&$ Noel, 1991) dual-route theory of reading aloud is that there are two ways of generating the pronunciation of a printed letter string. One is via a "lexical route" that involves the retrieval of the whole-word phonology stored in a phonological output lexicon (which is accessed via a connection from the orthographic input lexicon). The second is via a "nonlexical route" that computes phonology by means of application of letter-to-sound correspondence rules (i.e., rules that map graphemes onto phonemes). According to this theory, exception words, whose pronunciations do not follow these rules (e.g., pint, yacht), can be read aloud correctly only via the lexical route, whereas nonwords (e.g., slint), which are not represented in the orthographic input lexicon, can be read aloud correctly only via the nonlexical route.

Given this dual-route architecture, it seems plausible that readers could strategically shift the relative emphasis of the two routes in response to the nature of the stimulus list. In particular, because nonwords can only be

Thanks are due Judy Wilson and Anna Woollams for research assistance. We also thank reviewers Jason Zevin and Ilhan Raman and an anonymous reviewer for their helpful comments on the manuscript. Correspondence concerning this article may be addressed to S. Kinoshita, Macquarie Centre for Cognitive Science (MACCS), Macquarie University, Sydney, NSW 2109, Australia (e-mail: sachiko.kinoshita@ mq.edu.au). named by the nonlexical route, when the stimulus list consists primarily of nonwords, the nonlexical route may receive maximal emphasis. In contrast, because exception words are named incorrectly by the nonlexical route, when the stimulus list consists primarily of exception words, the nonlexical route would receive minimal emphasis. Performance, in both cases, would be essentially determined by the characteristics of the route having the stronger emphasis. ${ }^{1}$

Although the ability to shift route emphasis is not a feature required by any dual-route model, it is a concept that has been investigated enthusiastically over the past 20 years within the framework of such models (Coltheart, 1978; Lupker, Brown, \& Colombo, 1997; Monsell, Patterson, Graham, Hughes, \& Milroy, 1992; Paap \& Noel, 1991; Zevin \& Balota, 2000). In this article, we are interested specifically in two expected manifestations of shifting route emphasis. There are two well-known effects in the reading aloud literature - the regularity and lexicality effects - both of which document the interaction between the two routes. These effects were examined under two different conditions, representing situations in which the relative emphasis on the two routes should vary considerably.

The regularity effect refers to the finding that exception words such as pint are read aloud more slowly than are regular words such as pink. The size of the regularity effect is modulated by word frequency, such that the effect is much larger when words are of low rather than high frequency (Brown, Lupker, \& Colombo, 1994; Paap \& Noel, 1991; Seidenberg, Waters, Barnes, \& Tanen- 
haus, 1984). Within the dual-route theory, the regularity effect is explained in terms of a conflict between the pronunciation computed by the nonlexical route and that retrieved by the lexical route for the exception word-a conflict whose resolution takes time. The fact that the cost is greater for low-frequency words is explained by the assumption that, for high-frequency words, the stored pronunciation is retrieved so rapidly via the frequencysensitive lexical route that the slower nonlexical route does not cause a significant conflict. The size of the regularity effect, according to dual-route theory, is therefore a function of the temporal relationship between the two routes. It follows that if the nonlexical route were slowed down relative to the lexical route, there would be less conflict between them; hence, the regularity effect should decrease. Thus, to the extent that the relative emphasis on the two routes is under participants' control, dual-route theory would predict a smaller regularity effect under conditions that discourage reliance on the nonlexical route - in particular, within a block containing mainly exception words.

At present, there is little evidence of this predicted modulation of the regularity effect (Coltheart \& Rastle, 1994; Jared, 1997; Woollams \& Kinoshita, 1997). Coltheart and Rastle mixed low-frequency regular and exception target words with high-frequency exception word fillers or nonword fillers and found no effect of filler type on the size of the regularity effect. Similarly, Woollams and Kinoshita presented Coltheart and Rastle's target stimuli to participants mixed with either low-frequency exception word fillers or nonword fillers and again found no modulation in the size of the regularity effect as a function of filler type. Jared investigated the influence of filler condition on the consistency effect rather than the regularity effect (where consistency is defined by the body-rime mapping) and again found no difference. The size of the consistency effect was statistically equivalent in the nonword and low-frequency exception word filler conditions.

The only experiment showing the predicted modulation in the size of the regularity effect as a function of the nature of the stimulus list was reported by Zevin and Balota (2000). Using a procedure in which a series of five primes, either exception words or nonwords, were presented prior to each target, Zevin and Balota showed that the regularity effect was smaller following a series of exception word primes than following a series of nonword primes, as dual-route theory would predict. In an attempted replication, however, Kinoshita and Lupker (2003) failed to observe a pattern at all similar to Zevin and Balota's. Thus, on the basis of these studies examining the regularity effect, the conclusion would seem to be that strategic control of route emphasis does not occur in reading aloud (see also, e.g., Kinoshita \& Lupker, 2002).

The lexicality effect refers to the finding that latencies to words tend to be faster than latencies to nonwords. Here, following Zevin and Balota's (2000) work, we will define the lexicality effect specifically to refer to an ad- vantage of low-frequency exception words over nonwords. Within dual-route theory, this effect is explained by the assumption that a complete pronunciation is derived more quickly by the lexical route than by the nonlexical route. If readers are able to selectively emphasize either of the two routes, we would expect a larger lexicality effect under conditions that discourage reliance on the nonlexical route-specifically, within a block containing mainly exception words. This increase in the lexicality effect is expected because a decreased emphasis on the nonlexical route should both slow nonword naming and, because of lessened competition, speed exception word naming. Thus, the size of the lexicality effect should be modulated inversely from the size of the regularity effect: A reduced emphasis on the nonlexical route due to the presence of exception word fillers should lead to both a larger lexicality effect and a smaller regularity effect.

In contrast, reports in the literature indicate that the lexicality effect can be modulated as a function of filler type, in a manner that is consistent with dual-route theory. Using their multiple-prime procedure, Zevin and Balota (2000) showed that the lexicality effect was larger following a series of exception word primes than following a series of nonword primes, as dual-route theory would predict. Furthermore, in contrast to Zevin and Balota's regularity effect results, their lexicality effect results were replicated by Kinoshita and Lupker (2003). In addition, Kinoshita and Lupker's effects were independent of the speed with which their nonword primes were named. Thus, on the basis of these results, one could conclude that strategic shifting of route emphasis is possible in contexts that favor the lexicality effect, along the lines expected from the dual-route theory.

In summary, the support for the route-emphasis hypothesis is mixed: With the regularity effect, it seems that route emphasis cannot be shifted when reading aloud, but results based on the lexicality effect suggest the opposite conclusion. One way to explain this discrepancy would be to suggest that shifting route emphasis is not possible, and that the modulation of the lexicality effect reflects a different mechanism altogether-for example, a lexical checking strategy, as argued by Kinoshita and Lupker (2003; see also Lupker et al., 1997). The lexical checking account suggests that prior to emitting a reading aloud response, readers have the option of consulting the phonological output lexicon in order to determine whether the code generated by the phonological coding process matches a code in the lexicon. This strategy would be beneficial, in terms of catching and correcting potential errors, when the stimulus list contains many low-frequency exception words. When the stimulus list contains only nonwords, however, the strategy is not only useless (since nonwords do not have a representation in the phonological output lexicon), but also counterproductive, because of the time requirements of an unsuccessful check. Thus, this strategy seems more likely to be used in a list containing mainly exception 
words (or following a series of exception word primes) than in a list containing mainly nonwords (or following a series of nonword primes). As a result, nonword latencies would be slower following exception word primes than following nonword primes, leading to a larger lexicality effect.

Irrespective of whether the lexical checking hypothesis in particular provides a sufficient or parsimonious account of human behavior (see Kello \& Plaut, 2000, for a discussion), it would appear that evidence supporting the route emphasis hypothesis is fairly limited. What should be noted, however, is that no single study of strategic effects in reading aloud has ever demonstrated an absence of the regularity effect modulation in the presence of the lexicality effect modulation. It is therefore possible that the manipulations used to bias route emphasis were simply stronger in the studies investigating the lexicality effect than in those investigating the regularity effect. In fact, Rastle and Coltheart (1999) have made exactly that argument in their attempt to explain why Coltheart and Rastle (1994) failed to observe a modulation of the regularity effect.

Accordingly, the initial goal of the present research was empirical: We wished to test for the modulation of the regularity and lexicality effects, as a function of filler type simultaneously (i.e., in the same experiment). If a single filler type manipulation results in a modulation of the lexicality effect, but not of the regularity effect, then it cannot be argued that the filler type manipulation was insufficient to bias route emphasis. In that case, a different account of the lexicality effect modulation, perhaps a lexical checking account, would have to be developed. To this end, in the present experiment, participants read aloud low-frequency regular word, low-frequency exception word, and nonword targets in blocks containing either nonword fillers or low-frequency exception word fillers. The comparison between the regular and exception word targets provided a measure of the regularity effect, and that between the exception word and nonword targets provided a measure of the lexicality effect. The question was whether it is possible to observe a larger lexicality effect in the exception word filler block without a corresponding increase in the size of the regularity effect, a pattern that would be consistent with the previous literature.

\section{EXPERIMENT}

\section{Method}

Design. The present experiment constituted a 3 (target type: lowfrequency regular word, low-frequency exception word, or nonword) $\times 2$ (filler type: low-frequency exception word vs. nonword) factorial design, with both factors manipulated within subjects.

Participants. Twenty-four volunteer first-year psychology students from Macquarie University participated in the experiment in return for course credit.

Materials. The experimental targets were 30 low-frequency regular words, 30 low-frequency exception words, and 30 nonwords. All items were monosyllabic and between 4 and 6 letters long. The three types of items were matched on initial phoneme, number of letters, and $N$ (the number of orthographic neighbors of the same
Table 1

Stimulus Characteristics of Targets and Fillers Used

\begin{tabular}{lccc}
\hline & Length & Frequency & $N$ \\
\hline Targets & & & \\
$\quad$ Low-frequency regular word & 4.60 & 117.70 & 5.03 \\
$\quad$ Low-frequency exception word & 4.60 & 113.97 & 5.00 \\
$\quad$ Nonword & 4.60 & - & 5.07 \\
Fillers & & & \\
$\quad$ Low-frequency exception word & 4.80 & 106.18 & 3.17 \\
$\quad$ Nonword & 4.80 & - & 6.33 \\
\hline
\end{tabular}

Note-Length, item length (number of letters); Frequency, CELEX written frequency (per 18 million); $N$, number of orthographic neighbors.

length, Coltheart, Davelaar, Jonasson, \& Besner, 1977). The lowfrequency regular and exception words were also matched on frequency based on the CELEX lexical database (Baayen, Piepenbrock, \& van Rijn, 1993). These stimulus characteristics are shown in Table 1, and the items are listed in Appendix A.

In addition to the experimental targets, there were 45 exception word fillers and 45 nonword fillers. The two types of fillers were matched on length and initial phoneme. Their characteristics are also shown in Table 1, and the items are listed in Appendix B.

The experimental targets were divided into two equivalent sets, $\mathrm{A}$ and $\mathrm{B}$, each containing 15 low-frequency regular words, 15 lowfrequency exception words, and 15 nonwords. The assignments of sets to the two filler type blocks were counterbalanced across participants so that for half of the participants, Set A items appeared with the exception word fillers and Set B items appeared with the nonword fillers; for the other half of the participants, the assignments were reversed.

There were also 10 practice stimuli and 2 initial buffer stimuli in each filler type block that preceded the experimental stimuli. Practice and buffer stimuli consisted of the same type of fillers that were presented in the test block (i.e., either low-frequency exception words or nonwords), plus one low-frequency regular word, one lowfrequency exception word, and one nonword. None of the practice stimuli overlapped with the experimental stimuli.

Apparatus and Procedure. Each participant completed two blocks of trials, one containing the exception word fillers and the other containing the nonword fillers. Each block consisted of 10 practice items; 2 initial buffer items; and 90 test items consisting of 45 fillers - 15 low-frequency regular word targets, 15 low-frequency exception word targets, and 15 nonword targets. The order of the two filler blocks was counterbalanced across participants so that half of the participants saw the exception word filler block first and the other half saw the nonword filler block first. With the assignment of stimulus set to the filler type blocks counterbalanced as well, 4 participants constituted a fully counterbalanced group.

At the outset of the experiment, participants were told that a list of words and nonwords would be shown on the computer screen, one at a time. They were instructed to read aloud each item as quickly as possible without making too many errors.

Participants were tested individually and seated approximately $40 \mathrm{~cm}$ in front of an NEC MultiSync 4FG monitor upon which the stimuli were presented. Instructions and stimuli were displayed and reaction time (RT) data recorded to the nearest millisecond using the DMASTR display system developed by Forster and Forster at Monash University, Australia, and the University of Arizona (details of this system can be obtained at http://www.u.arizona.edu/ $\sim$ kforster/dmastr/dmastr.htm) running on a DeltaCom 486 IBMcompatible computer. RTs were recorded using a voice key headset, fitted to each participant and held a constant distance from the mouth, which triggered when a criterial level of amplitude was reached. The voice key was calibrated for each participant prior to the experiment and was not recalibrated at any time during the testing session. Voice key and participant errors were recorded manually by the experi- 
menter. Each trial started with the presentation of a target, which remained on the screen for $200 \mathrm{msec}$ or until the participant's response. After a 500 msec blank interval, the next trial started.

\section{Results and Discussion}

Prior to analysis, RT and error data were treated in the following manner: Any trial on which a participant or voice key error occurred was excluded from the latency analysis. In order to reduce effects of outliers, spuriously long or short reaction times were trimmed to the cutoff value of two standard deviations above or below the mean for each subject. This procedure affected $4.53 \%$ of the total number of trials. Analyses treating both subjects $\left(F_{1}\right)$ and items $\left(F_{2}\right)$ as random variables are reported. The .05 level was used to determine significance in all cases. For both naming latency and percentage error rate, we first report a 3 (target type) $\times 2$ (filler type) analysis of variance (ANOVA) and then report planned contrasts testing the regularity effect (regular vs. exception words), the lexicality effect (exception words vs. nonwords), and the interactions between these factors and filler type (regularity $\times$ filler type; lexicality $\times$ filler type). In the subject analyses, both target type and filler type were treated as repeated factors; in the item analyses, target type was treated as a nonrepeated factor and filler type, as a repeated factor. The mean naming latencies and percentage error rates from the subject analysis are presented in Table 2 .

Targets. For latency, the main effect of filler type was significant $\left[F_{1}(1,23)=12.40, M S_{\mathrm{e}}=2,790.75\right.$; $\left.F_{2}(1,87)=23.75, M S_{\mathrm{e}}=1,625.11\right]$, as was the main effect of target type $\left[F_{1}(2,23)=39.53, M S_{\mathrm{e}}=1,454.79\right.$; $\left.F_{2}(2,87)=15.63, M S_{\mathrm{e}}=4,037.04\right]$. The interaction between filler type and target type was also significant $\left[F_{1}(2,46)=7.54, M S_{\mathrm{e}}=655.72 ; F_{2}(2,87)=3.80\right.$, $\left.M S_{\mathrm{e}}=1,625.11\right]$. Planned contrasts showed that averaged over the filler type, there were significant regularity $\left[F_{1}(1,23)=74.39, M S_{\mathrm{e}}=1,454.79 ; F_{2}(1,87)=9.95\right.$, $\left.M S_{\mathrm{e}}=4,037.04\right]$ and lexicality $\left[F_{1}(1,23)=19.29\right.$, $\left.M S_{\mathrm{e}}=1,454.79 ; F_{2}(1,87)=5.86, M S_{\mathrm{e}}=4,037.04\right]$ effects. As predicted, the lexicality effect was significantly larger in the exception word filler condition than in the nonword filler condition $\left[F_{1}(1,23)=6.51, M S_{\mathrm{e}}=655.72\right.$; $\left.F_{2}(1,87)=3.78, M S_{\mathrm{e}}=1,625.11\right]($ see Table 2$) .{ }^{2}$ As Table 2 also shows, contrary to the route emphasis pre- diction, the regularity effect was also larger in the exception word filler condition than in the nonword filler condition, although planned contrasts showed that this trend was nonsignificant $\left[F_{1}(1,23)=1.59, M S_{\mathrm{e}}=655.72\right.$; $\left.F_{2}(1,87)<1.0\right]$.

For errors, the main effect of filler type was nonsignificant $\left[F_{1}(1,23)<1.0, M S_{\mathrm{e}}=0.29 ; F_{2}(1,87)<1.0\right.$, $\left.M S_{\mathrm{e}}=37.39\right]$. The main effect of target type was significant $\left[F_{1}(2,23)=32.44, M S_{\mathrm{e}}=74.29 ; F_{2}(2,87)=8.68\right.$, $\left.M S_{\mathrm{e}}=347.25\right]$. Planned contrasts showed that averaged over filler type, the regularity effect was significant $\left[F_{1}(1,23)=61.02, M S_{\mathrm{e}}=74.29 ; F_{2}(1,87)=16.34\right.$, $\left.M S_{\mathrm{e}}=347.25\right]$. There was also a reverse lexicality effect (more accurate responses to nonwords than to exception words) that reached significance by subjects $\left[F_{1}(1,23)=\right.$ 4.87, $\left.M S_{\mathrm{e}}=74.29\right]$ but not by items $\left[F_{2}(1,87)=1.31\right.$, $\left.M S_{\mathrm{e}}=347.25\right]$. The interaction between filler type and target type was nonsignificant $\left[F_{1}(2,23)<1.0, M S_{\mathrm{e}}=\right.$ $\left.63.62 ; F_{1}(2,87)=1.57, M S_{\mathrm{e}}=37.39\right]$. Regularity did not interact with filler type $\left[F_{1}(1,23)<1.0 ; F_{2}(1,87)<1.0\right]$; however, the reverse lexicality effect was slightly larger in the nonword filler block, an effect that was significant by subjects $\left[F_{1}(1,23)=5.69, M S_{\mathrm{e}}=63.62\right]$ and marginal by items $\left[F_{2}(1,87)=3.05, M S_{\mathrm{e}}=37.39, p=.08\right]$.

Fillers. For latency, the effect of filler type was marginally significant by subjects $\left[F_{1}(1,23)=4.13, M S_{\mathrm{e}}=\right.$ $762.65, p=.053]$ but nonsignificant by items $\left[F_{2}(1,88)=\right.$ $\left.1.68, M S_{\mathrm{e}}=3,919.99\right]$. For errors, the main effect of filler type was significant $\left[F_{1}(1,23)=11.50, M S_{\mathrm{e}}=35.68\right.$; $\left.F_{2}(1,88)=4.87, M S_{\mathrm{e}}=295.47\right]$.

The results of this experiment are clear. As predicted, the lexicality effect was significantly larger in the exception word filler condition than in the nonword filler condition. However, contrary to predictions, the regularity effect was not significantly smaller in the exception word filler condition than in the nonword filler condition. In fact, numerically, it was noticeably larger in the exception word filler condition (52 $\mathrm{msec}$ vs. $38 \mathrm{msec}$ ). Results like these have been observed separately in previous studies, but this is the first demonstration of the two patterns occurring simultaneously. Therefore, it cannot be argued that the consistent failure to find a modulation of the regularity effect as a function of filler type in the past has been due to an insufficiently strong manipulation of filler type.

Table 2

Mean Naming Latencies (RTs, in Milliseconds) and Percentage Errors (\%E) in the Experiment

\begin{tabular}{|c|c|c|c|c|c|c|}
\hline & \multicolumn{2}{|c|}{ Nonword Filler } & \multicolumn{2}{|c|}{ Exception Word Filler } & \multicolumn{2}{|c|}{ Difference } \\
\hline & RT & $\% \mathrm{E}$ & RT & $\% \mathrm{E}$ & RT & $\% \mathrm{E}$ \\
\hline \multicolumn{7}{|l|}{ Target type } \\
\hline Nonword & 579 & 9.7 & 632 & 11.9 & -53 & -2.2 \\
\hline Low-frequency regular word & 531 & 1.1 & 544 & 0.8 & -13 & 0.3 \\
\hline Low-frequency exception word & 569 & 15.6 & 596 & 13.9 & -27 & 1.7 \\
\hline Regularity effect & 38 & 14.5 & 52 & 13.1 & & \\
\hline Lexicality effect & 10 & -5.9 & 36 & -2.0 & & \\
\hline Filler & 555 & 5.3 & 572 & 11.1 & & \\
\hline
\end{tabular}




\section{DUAL-ROUTE CASCADED (DRC) SIMULATION}

The results of this experiment appear incompatible with the idea of strategic shifting of route emphasis within the framework of dual-route theory. We note, however, that we have so far considered only verbal descriptions of the dual-route theory in discussing predictions of the route-emphasis hypothesis. This is also true for each of the previous studies that we have discussed (e.g., Coltheart \& Rastle, 1994; Jared, 1997; Monsell et al., 1992; Zevin \& Balota, 2000). Recent demonstrations (e.g., Zorzi, 2000) have shown that predictions from computationally implemented models can only really be derived through simulations. Because an implementation of the dual-route theory of reading is available - the DRC model (Coltheart et al., 2001) —an obvious next step would be to verify the predictions outlined in the introduction.

\section{Method}

The target items used in the human reading aloud experiment (30 low-frequency exception words, 30 low-frequency regular words, and 30 nonwords matched on initial phoneme, length, and $N$ ) were used as stimuli in the simulation. We simulated the impact of the filler type manipulation in the DRC model by reducing the influence of the nonlexical route in the exception word filler condition relative to the standard set of parameters that control the model (see also Rastle \& Coltheart, 1999). That is, the assumptions were made that the standard parameter settings represent the situation in the nonword filler condition and that a reduction in the influence of the nonlexical route would be expected in the exception word filler condition.

There are three parameters that control the influence of the nonlexical route in the DRC model. The first is the GPC interletter in- terval parameter. This parameter sets the lag between the beginning of processing on letter $n$ and the beginning of processing on letter $n+1$ by the nonlexical route; that is, this parameter controls how soon each letter is made available to the serially operating GPC translation system. Its default setting is 17 cycles. Next is the GPC activation offset parameter, which determines how many cycles must elapse before the nonlexical route can begin to operate upon the first letter in the stimulus. Its default setting is 10 cycles. The final parameter controls GPC excitation, which is the strength of nonlexical activation passed to the phoneme units from the letter units. Its default setting is .055 . Modification of any of these parameters can increase or reduce the influence of the nonlexical route. Specifically, in order to model the decreased impact of the nonlexical route in the exception word filler condition, both the GPC activation offset and GPC interletter interval parameters were increased, and the GPC excitation parameter was decreased. The question is, what are the consequences of modifications of these parameters on the predicted sizes of the regularity and lexicality effects?

\section{Results and Discussion}

Six of the stimuli had to be excluded from these simulation analyses for the following reasons: Three nonwords, grung, kogue, and clase, were read aloud incorrectly in all simulations; the words chasm and huddle are disyllabic and, hence, are not in the DRC model's lexicon; and the word guild, though included in the exception word condition in the experiment, is considered regular according to the DRC model's current set of rules. Remaining DRC reading aloud latencies (in cycles) at a number of values for each parameter are displayed in Table 3.

As shown in Table 3, decreasing the influence of the nonlexical route-irrespective of the parameter modification by which this is accomplished - leads to a decrease in the size of the regularity effect and to an increase in the

Table 3

Mean Naming Latencies (in DRC Processing Cycles) as a Function of Target Type and Parameter Change

\begin{tabular}{|c|c|c|c|c|c|c|c|}
\hline & \multicolumn{6}{|c|}{ GPC Interletter Interval } & \\
\hline & 17 (Normal Model) & 18 & 19 & 20 & 21 & \multicolumn{2}{|l|}{22} \\
\hline Exception words & 86.18 & 85 & 85. & 84.82 & 84.43 & 83.82 & \\
\hline Regular words & 77.52 & 77. & 77. & 77.97 & 77.97 & 78.14 & \\
\hline Nonwords & 156.19 & 160 & 165. & $\begin{array}{ll}3 & 171.93\end{array}$ & 177.26 & 182.11 & \\
\hline Regularity effect & 8.66 & & 5 & 6.86 & 6.46 & 5.68 & \\
\hline \multirow[t]{3}{*}{ Lexicality effect } & 70.01 & 75 & 80. & 87.11 & 92.83 & 98.29 & \\
\hline & \multicolumn{6}{|c|}{ GPC Offset Activation } & \\
\hline & 10 (Normal Model & 1) & 12 & 13 & 14 & 15 & \\
\hline Exception words & 86.18 & 85 & 85 . & 84.86 & 84.39 & 83.89 & \\
\hline Regular words & 77.52 & 77 & 77. & 77.66 & 77.66 & 77.76 & \\
\hline Nonwords & 156.19 & 156 & 6157. & $9 \quad 158.89$ & 159.67 & 160.48 & \\
\hline Regularity effect & 8.66 & & & 7.20 & 6.74 & 6.13 & \\
\hline \multirow[t]{3}{*}{ Lexicality effect } & 70.01 & 71 & 72. & 74.03 & 75.28 & 76.59 & \\
\hline & \multicolumn{7}{|c|}{ GPC Excitation } \\
\hline & $\begin{array}{c}0.055 \\
\text { (Normal Model) }\end{array}$ & 0.0549 & 0.054 & 0.053 & 0.052 & 0.051 & 0.05 \\
\hline Exception words & 86.18 & 86.18 & 85.89 & 85.57 & 85.39 & 85.04 & 84.79 \\
\hline Regular words & 77.52 & 77.52 & 77.45 & 77.41 & 77.41 & 77.45 & 77.45 \\
\hline Nonwords & 156.19 & 156.41 & 157.26 & 158.48 & 159.52 & 160.74 & 161.96 \\
\hline Regularity effect & 8.66 & 8.66 & 8.44 & 8.16 & 7.98 & 7.59 & 7.34 \\
\hline Lexicality effect & 70.01 & 70.23 & 71.37 & 72.91 & 74.13 & 75.70 & 77.17 \\
\hline
\end{tabular}


size of the lexicality effect. Thus, in terms of the main issues under investigation here, Table 3 clearly shows that the impact of parameter modification is consistent with what is expected according to verbal descriptions of the DRC model.

Statistical analyses involving only single-step changes in the parameter settings (changing the GPC interletter interval parameter from 17 to 18 , the GPC activation offset parameter from 10 to 11 , or the GPC excitation parameter from .055 to .054) further confirm this observation. These analyses were carried out in the same manner as with the human data: A 3 (target type) $\times 2$ (filler type) ANOVA is reported first, followed by planned contrasts examining the size of the regularity and lexicality effects under different simulated filler conditions.

For the GPC interletter interval parameter (changed from 17 to 18 cycles), the $3 \times 2$ ANOVA revealed a main effect of target type $\left[F(2,81)=207.64, M S_{\mathrm{e}}=525.89\right]$, a main effect of filler type $\left[F(1,81)=61.67, M S_{\mathrm{e}}=\right.$ $1.42]$, and an interaction $\left[F(2,81)=77.81, M S_{\mathrm{e}}=1.42\right]$. When exception words and regular words were compared, a main effect of regularity emerged $[F(1,55)=38.19$, $\left.M S_{\mathrm{e}}=51.48\right]$, but unlike the human data, this effect was modulated by filler type $\left[F(1,55)=18.62, M S_{\mathrm{e}}=0.192\right]$. When exception words and nonwords were compared, a main effect of lexicality emerged $[F(1,53)=181.67$, $\left.M S_{\mathrm{e}}=798.19\right]$, and this effect was modulated by filler type $\left[F(1,53)=89.84, M S_{\mathrm{e}}=2.10\right]$.

For the GPC activation offset parameter (changed from 10 to 11 cycles), the $3 \times 2$ ANOVA revealed a main effect of target type $\left[F(2,81)=214.81, M S_{\mathrm{e}}=483.24\right]$, a main effect of filler type $\left[F(1,81)=4.22, M S_{\mathrm{e}}=0.133\right]$, and an interaction $\left[F(2,81)=42.34, M S_{\mathrm{e}}=0.133\right]$. When exception words and regular words were compared, a main effect of regularity emerged $\left[F(1,55)=38.91, M S_{\mathrm{e}}=\right.$ 51.38], but again this effect was modulated by filler type $\left[F(1,55)=19.72, M S_{\mathrm{e}}=0.117\right]$. When exception words and nonwords were compared, a main effect of lexicality emerged $\left[F(1,53)=187.08, M S_{\mathrm{e}}=733.40\right]$, and this effect was also modulated by filler type $[F(1,53)=67.33$, $\left.M S_{\mathrm{e}}=0.167\right]$.

Finally, for the GPC excitation parameter (changed from 0.055 to 0.054 ), the $3 \times 2$ ANOVA revealed a main effect of target type $\left[F(2,81)=215.38, M S_{\mathrm{e}}=483.82\right]$, a main effect of filler type $\left[F(1,81)=22.43, M S_{\mathrm{e}}=\right.$ $0.11]$, and an interaction $\left[F(2,81)=68.03, M S_{\mathrm{e}}=0.11\right]$. When exception words and regular words were compared, a main effect of regularity emerged $[F(1,55)=$ $\left.39.91, M S_{\mathrm{e}}=52.23\right]$, and the modulation of this effect by filler type just missed significance $[F(1,55)=3.84$, $p=.055]$. When exception words and nonwords were compared, a main effect of lexicality emerged $[F(1,54)=$ $\left.157.68, M S_{\mathrm{e}}=962.59\right]$, and this effect was modulated by filler type $\left[F(1,54)=79.15, M S_{\mathrm{e}}=0.154\right]$. Thus, regardless of how the parameter change is envisioned, the human data pattern is not compatible with the routeemphasis hypothesis implemented within the DRC model.
One point to note about the simulations is that the predicted changes in latency were always largest for the nonwords. This fact suggests that it might be possible to alter the parameter values in such a way that the model could predict a change in the size of the lexicality effect (due to a change in nonword latency) but no change in the size of the regularity effect. This parameter alteration would, of course, have to be a very small one. The unit of both the GPC activation offset and the GPC interletter interval parameters is number of cycles, with a step size of one. Thus, there is no way to make a smaller change than one unit to either of these parameters. The GPC excitation parameter, however, is a continuous parameter, and hence, changes of any magnitude are possible. As Table 3 indicates, if this parameter is changed from 0.055 to 0.0549 , there is an increase in the lexicality effect [from 70.01 cycles to 70.23 cycles; $F(1,53)=$ $7.71, M S_{\mathrm{e}}=0.044$ ) because of the slowdown of the nonwords. At the same time, there is no change in the size of the regularity effect ( 8.66 cycles in both cases).

Does this final analysis, then, indicate that the routeemphasis hypothesis can be made consistent with the present data? We will consider this issue further in the general discussion, and here simply draw the reader's attention to the following facts: First, in the above simulation, the change in the size of the lexicality effect is out of scale with the size of the effect itself. If the lexicality effect of 70.01 cycles under the standard parameter setting is assumed to correspond to the effect of $10 \mathrm{msec}$ that was observed in the nonword filler condition, then the change in the lexicality effect from 70.01 cycles to 70.23 cycles $(0.22$ cycles $)$ represents an increase of $0.03 \mathrm{msec}$, to $10.03 \mathrm{msec}$, rather than the increase from 26 to $36 \mathrm{msec}$ that was actually observed. Thus, even this very limited change in the GPC excitation parameter cannot be said to successfully simulate the complete human data.

Second, note that, according to this simulation, the lexicality effect in the nonword filler condition is 70.01 cycles, whereas the regularity effect is only 8.66 cycles. This relationship (massively larger lexicality effect relative to the size of the regularity effect) is actually observed at all levels of parameter settings. In the human data, however, the relationship is reversed, with the regularity effect being larger than the lexicality effect (the regularity effect is $38 \mathrm{msec}$ and the lexicality effect is $10 \mathrm{msec}$ in the nonword filler condition, whereas the effects are $52 \mathrm{msec}$ and $36 \mathrm{msec}$, respectively, in the exception word filler condition). It seems unlikely that there would be any way of scaling the effect sizes in the model to allow it to account simultaneously for the sizes of the regularity and lexicality effects.

\section{GENERAL DISCUSSION}

In this article, we investigated two predictions of the route-emphasis hypothesis within dual-route theories of 
reading - that biasing against nonlexical processing through a filler type manipulation would result in a decreased regularity effect and an increased lexicality effect. Our results revealed that such bias affected only the size of the lexicality effect. The size of the regularity effect did not change in the predicted direction.

Empirically, our findings are important because in a single experiment, they demonstrate a modulation of the lexicality effect without a corresponding modulation of the regularity effect. Although a number of previous studies (e.g., Coltheart \& Rastle, 1994; Jared, 1997; Lupker et al., 1997; Monsell et al., 1992; Woollams \& Kinoshita, 1997) have suggested this pattern of data, it remained possible that the failures to modulate the regularity effect were due to an ineffective modulation of route emphasis (as argued by, for example, Rastle \& Coltheart, 1999). Our findings are immune to this criticism: If the fillertype manipulation was sufficiently effective to modulate the lexicality effect, it should also have been sufficiently effective to modulate the regularity effect.

Through our simulations using the DRC model, we have also examined whether this potential theoretical mechanism - route emphasis - can possibly account for the observed effects. In past studies, predictions of the routeemphasis hypothesis have been based upon verbal descriptions of dual-route theories (e.g., Coltheart \& Rastle, 1994; Jared, 1997; Woollams \& Kinoshita, 1997). On the basis of these verbal descriptions, one would have concluded that the present results are inconsistent with the route-emphasis hypothesis. What the simulations show is that this conclusion is generally correct. Only when a minor alteration was made in one of the parameters of the nonlexical route was there any suggestion that one could predict a change in size of the lexicality effect without a simultaneous change in the size of the regularity effect. Even then, however, the model failed to explain the general pattern of data, for the predicted sizes of the effects were way out of scale: The predicted size modulation of the lexicality effect relative to the size of that effect was disproportionately smaller than in the human data. Also, the model predicted that the lexicality effect should be substantially larger than the regularity effect, whereas the human data showed the opposite relationship (i.e., the regularity effect was larger than the lexicality effect).

In terms of understanding the DRC model, it is of course useful to consider why reducing the influence of the nonlexical route in the model has greater consequences for the size of the lexicality effect than for that of the regularity effect. The answer, essentially, is that the nonlexical route's contribution to the naming latency of words is relatively small, whereas correct reading of nonwords is absolutely dependent upon nonlexical processing. That is, although the nonlexical route's contributions slow down responding for exception words, this is true only when the words are low in frequency and have early irregularities (see Rastle \& Coltheart, 1999). In addition, the nonlexical route does not appreciably speed up the reading aloud of regular words. (See Rastle \& Coltheart's, 1999, conclusion on this issue, as well as Paap \& Noel's, 1991, alternative position.) In contrast, any reduction in the influence of the nonlexical route is particularly devastating for nonwords and thus, changes the size of the lexicality effect dramatically. The DRC model therefore makes the strong prediction that a bias against nonlexical processing in human readers would always have a greater impact on nonwords than words. Indeed, in every simulation that we produced, adjustments to nonlexical processing had greater consequences for the size of the lexicality effect than for that of the regularity effect. Could it be argued, then, that the DRC simulation captures qualitatively the essential aspect of the present human data - that filler type manipulations affect nonwords more than words?

In considering this question, it is of interest to discuss the previous empirical and simulation work of Rastle and Coltheart (1999), who also attempted to bias human readers against nonlexical processing and produced a simulation of their results within the route-emphasis framework using the DRC model. Rastle and Coltheart presented human readers with nonword and regular word targets under two filler conditions-exception words with late irregularities (e.g., glow) and exception words with early irregularities (e.g., chef). According to the DRC model, exception words with early irregularities are particularly prone to latency or accuracy costs because of the influence of the serially operating nonlexical route. Readers should therefore be especially keen to reduce the influence of the nonlexical route when such fillers are present, causing slowed processing of nonwords and (possibly) regular words. As predicted, results showed slowed nonword reading in the presence of the exception words with early irregularities, as well as slowed regular word reading. Although regular word reading was slowed to a lesser degree numerically than nonword reading, there was no interaction between lexical status and filler condition; statistically speaking, nonwords and regular words were slowed equally.

Rastle and Coltheart (1999) attempted a simulation of this result by reducing the influence of the nonlexical route by altering the GPC interletter interval parameter. Critically, in order to produce a significant slowing of regular words, Rastle and Coltheart had to implement a massive five-cycle adjustment to this parameter, increasing the interletter interval parameter from 17 to 22 cycles. As can be seen in Table 3, this degree of adjustment produces a far greater predicted change in latencies than changing the GPC excitation parameter from 0.055 to 0.0549 . Thus, it would not produce a successful simulation of the present data. Furthermore, Rastle and Coltheart found that although this level of adjustment did predict a slowing of regular words, the DRC model also predicted a massive interaction between lexical status and filler condition - with nonwords being far more affected by filler type than regular words. It would have 
to be concluded, therefore, that this simulation did not successfully capture the filler type effect reported by Rastle and Coltheart. (See Chateau and Lupker, 2003, for an alternative explanation of Rastle and Coltheart's results.)

It is also likely that the DRC model's assumption that the nonlexical route's contribution to the reading of words is relatively small explains the model's misprediction of the scale of the lexicality effect. In the present simulations, the DRC model produced a massive lexicality effect relative to the changes in size of both that effect and the regularity effect, a result that is considerably out of step with the human data. That is, within the DRC model, the nonlexical route is too slow relative to the lexical route. The solution to this problem would be to change the default parameter settings to increase the speed of the nonlexical route. However, given that the default parameter values were chosen specifically to account for the correct reading of exception words and nonwords simultaneously (see Coltheart et al., 2001, pp. 218-219), it would not be a trivial matter to find an alternative set of parameter values that would speed up the nonlexical route, reducing the predicted lexicality effect, without affecting how well the model accounts for the benchmark phenomena that are currently well simulated. (See Coltheart et al., 2001, p. 220, for a list of these phenomena.) Thus, although the DRC does capture qualitatively an essential aspect of the present results, the finding that our filler type manipulation affects nonwords more than words, it appears to do so with considerable cost to its ability to predict other aspects of those, and other, results.

More recently, the notion of strategic alteration of route emphasis has been considered within the framework of PDP models of reading aloud (Zevin \& Balota, 2000). These models also have multiple routes to pronunciation, one leading directly from orthography to phonology (the $\mathrm{O} \rightarrow \mathrm{P}$ route) and one leading from orthography to phonology through semantics (the $\mathrm{O} \rightarrow \mathrm{S} \rightarrow$ P route). The former route is the only route useful for naming nonwords, but the latter route is quite helpful when naming exception words. Thus, the filler type manipulation used here would also allow an examination of whether shifting route emphasis is a viable concept within those types of models as well. In particular, if route emphasis were shifted as would be expected, one should observe faster naming of nonwords in the nonword filler condition and faster naming of exception words in the exception word filler condition. (The naming of regular words is supported by both routes, and hence it wouldn't be possible to make clear predictions about how their latencies would be affected without running a simulation.) The result of shorter latencies for nonwords in the nonword filler condition is consistent with this prediction, but the result of shorter latencies for exception words in the exception word filler condition is not. Thus, although we have examined no simulations here, it seems unlikely that such models could account for the present pattern of data, either. ${ }^{3}$

What seems to be a better way of explaining the present results would be to think in terms of the two ideas put forth by Lupker et al. (1997) and since expanded upon by Taylor and Lupker (2001), Chateau and Lupker (2003), and Kinoshita and Lupker (2003). The first idea is that of a time criterion. As shown in these articles, in naming tasks, the latencies of a set of target stimuli are affected by the latencies of the other stimuli in the trial block. The easier to name those other stimuli are, as indexed by their latencies, the faster participants will name the target stimuli. Thus, at least some of the decrease in latencies from the exception word filler block to the nonword filler block is likely due to the fact that the nonword fillers had shorter latencies (i.e., $555 \mathrm{msec}$ ) than the exception word fillers (572 msec).

The reason that nonwords showed the largest impact of the filler type manipulation is explained by the other idea, lexical checking (see Borowsky, Owen, \& Masson, 2002, for a similar idea). Prior to emitting a response, participants have the option of checking the generated phonological code to make sure that it has a representation in a phonological output lexicon (i.e., that it is a real word). This is an error-control mechanism and would be especially useful when a large proportion of the stimuli are exception words - that is, words that have unusual grapheme-phoneme mappings - as in the exception word filler condition. Furthermore, the impact of this strategy on word latencies is small. That is, for word targets, the search of the phonological lexicon will rapidly turn up the fact that the pronunciation about to be given is the pronunciation of a real word. Thus, words would not be expected to show a large latency cost when using this strategy. For nonwords, however, the cost of using the strategy is much greater, because the search, which does take time, will fail to turn up a pronunciation. When the fillers are nonwords, and hence when most of the stimuli do not have representations in the phonological output lexicon, the strategy would necessarily be counterproductive. Thus, it should be used much less frequently in the nonword filler condition, and as a result, nonwords in particular will have shorter latencies in that condition.

Because there is no computational model incorporating both the notions of a time criterion and lexical checking, it is not entirely clear that such a model could completely capture the nature of the present results. Nonetheless, these ideas would seem to provide a much better way of looking at the data than either a route emphasis hypothesis, such as the one simulated in the DRC, or any another two-route model. In any case, the present data do make clear that any models that hope to explain strategic effects on reading aloud will have to explain the fact that filler type manipulations can modulate the size of the lexicality effect without simultaneously having much impact on the size of the regularity effect. 


\section{REFERENCES}

BaAyen, R. H., Piepenbrock, R., van Rijn, H. (1993). CELEX lexical database (CD-ROM). Philadelphia: Linguistic Database Consortium, University of Pennsylvania.

Borowsky, R., Owen, W. J., \& Masson, M. E. J. (2002). Diagnostics of phonological lexical processing: Pseudohomophone naming advantages, disadvantages, and base-word frequency effects. Memory \& Cognition, 30, 969-987.

BROWN, P., LUPKER, S. J., \& CoLOMBO, L. (1994). Sources of information in word naming: A study of individual differences. Journal of Experimental Psychology: Human Perception \& Performance, 20, 537-554.

Chateau, D., \& Lupker, S. J. (2003). Strategic effects in word naming: Examining the route-emphasis versus time-criterion accounts. Journal of Experimental Psychology: Human Perception \& Performance, 29, 139-151.

COLTHEART, M. (1978). Lexical access in simple reading tasks. In G. Underwood (Ed.), Strategies of information processing (pp. 151216). New York: Academic Press.

Coltheart, M., Curtis, B., Atkins, P., \& Haller, M. (1993). Models of reading aloud: Dual-route and parallel-distributed processing approaches. Psychological Review, 100, 589-608.

Coltheart, M., Davelaar, E., Jonasson, J. T., \& Besner, D. (1977). Access to the internal lexicon. In S. Dornic (Ed.), Attention and performance VI (pp. 535-555). Hillsdale, NJ: Erlbaum.

Coltheart, M., \& Rastle, K. (1994). Serial processing in reading aloud: Evidence for dual-route models of reading. Journal of Experimental Psychology: Human Perception \& Performance, 20, $1197-$ 1211

Coltheart, M., Rastle, K., Perry, C., Langdon, R., \& Ziegler, J. (2001). DRC: A dual route cascaded model of visual word recognition and reading aloud. Psychological Review, 108, 204-256.

JARED, D. (1997). Evidence that strategy effects in word naming reflect changes in output timing rather than changes in processing route. Journal of Experimental Psychology: Learning, Memory, \& Cognition, 23, 1424-1438.

KELLO, C. T., \& PlAUT, D. C. (2000). Strategic control in word naming: Evidence from speeded responding in the tempo-naming task. Journal of Experimental Psychology: Learning, Memory, \& Cognition, 26, 719-750.

KINOSHITA, S., \& LUPKER, S. J. (2002). Effects of filler type in naming: Change in time criterion or attentional control of pathways? Memory \& Cognition, 30, 1277-1287.

KinOSHITA, S., \& LuPKer, S. J. (2003). Priming and attentional control of lexical and sublexical pathways in naming: A reevaluation. Journal of Experimental Psychology: Learning, Memory, \& Cognition, 29, 405-415.

LuPKER, S. J., Brown, P., \& Colombo, L. (1997). Strategic control in a naming task: Changing routes or changing deadlines? Journal of Experimental Psychology: Learning, Memory, \& Cognition, 23, 570590.

Monsell, S., Patterson, K. E., Graham, A., Hughes, C. H., \& MilROY, R. (1992). Lexical and sublexical translations of spelling to sound: Strategic anticipation of lexical status. Journal of Experimental Psychology: Learning, Memory, \& Cognition, 18, 452-467.

PAAP, K. R., \& NoEL, R. W. (1991). Dual-route models of print to sound: Still a good horse race. Psychological Research/Psychologische Forschung, 53, 13-24.

Rastle, K., \& ColTheart, M. (1999). Serial and strategic effects in reading aloud. Journal of Experimental Psychology: Human Perception \& Performance, 25, 482-503.

SeIDENBerg, M. S., Waters, G. S., Barnes, M. A., \& Tanenhaus, M. K. (1984). When does irregular spelling or pronunciation influence word recognition? Journal of Verbal Learning \& Verbal Behavior, 23, 383-404.

TAYLOR, T. E., \& LUPKER, S. J. (2001). Sequential effects in naming: A time-criterion account. Journal of Experimental Psychology: Learning, Memory, \& Cognition, 27, 117-138.

WoOllams, A. M., \& Kinoshita, S. (1997). Strategic modification of response criterion for initiation of articulation in speeded naming. Paper presented at the 24th Annual Experimental Psychology Conference, Deakin University, Geelong, Victoria, Australia.

Zevin, J. D., \& Balota, D. A. (2000). Priming and attentional control of lexical and sublexical pathways during naming. Journal of Experimental Psychology: Learning, Memory, \& Cognition, 26, 121-135.

ZoRZI, M. (2000). Serial processing in reading aloud: No challenge for parallel models. Journal of Experimental Psychology: Human Perception \& Performance, 26, 847-856.

\section{NOTES}

1. A general assumption behind this theory is that the lexical route is more automatized than the nonlexical route (Monsell, Patterson, Graham, Hughes, \& Milroy, 1992; Paap \& Noel, 1991; Rastle \& Coltheart, 1999) and, hence, less susceptible to strategic control. For purposes of both our discussion and our simulation, we adopt that assumption here as well.

2. Although we followed Zevin and Balota (2000) in defining the lexicality effect as the difference between nonwords and exception words, the effect could also be operationalized as the difference between nonwords and regular words. We note that the lexicality effect also varied as a function of filler type when defined in the latter way $\left[F_{1}(1,23)=\right.$ $\left.14.52, M S_{\mathrm{e}}=655.72 ; F_{2}(1,87)=7.02, M S_{\mathrm{e}}=1,642.11\right]$.

3 . We should also note that within the currently implemented PDP models, the factor relevant to the speed of the $\mathrm{O} \rightarrow \mathrm{P}$ route is the consistency of body-to-rime mappings, not the regularity of grapheme to phoneme mappings that was manipulated here. (There is, however, a natural covariation between the two factors.) 
APPENDIX A

Target Stimuli

\section{Low-frequency regular words}

bait, shun, carve, cream, doom, droop, flip, glide, hoarse, helm, plum, roach, surge, sleek, wink, bulb, broth, coach, creep, cage, dump, fuss, goose, huddle, pulp, prune, roast, sheen, sock, wipe

\section{Low-frequency exception words}

beau, chef, chord, cough, deaf, dough, fete, guild, hearse, hood, pear, realm, seize, suite, wolf, bowl, blown, caste, chasm, comb, debt, feud, guise, hearth, pint, plaid, reign, shove, soot, womb

\section{Nonwords}

barv, shif, curlt, clase, dimp, detch, falp, ghief, horgue, hosh, pell, romph, sloob, seash, werg, bule, blint, carge, kogue, cume, derb, firb, grung, morque, poil, prape, rilch, sheem, sace, wult

\section{APPENDIX B}

Filler Stimuli

\section{Low-frequency exception word fillers}

aisle, aunt, axe, brooch, bury, choir, chute, couth, crepe, draught, dread, flood, flown, gaol, ghoul, glove, glow, gnome, heir, hoof, leapt, mould, niche, pearl, pique, psalm, rogue, sew, sheik, shoe, sieve, sleight, sown, sponge, spook, steak, suave, suede, swamp, sweat, sword, tomb, tsar, wool, yacht

\section{Nonword fillers}

anks, antle, ard, bame, blouch, canks, cound, crope, darge, drestle, enst, fitch, flink, gart, gotch, gream, gurp, hond, jort, leath, morst, norld, pench, plang, raste, seft, sheft, shipe, shud, sim, sking, slaid, sloon, smank, smeed, spant, spooch, spudge, srope, steen, sunch, tard, thore, wike, yeach

(Manuscript received November 24, 2003;

revision accepted for publication March 12, 2004.) 